Int. J. Adv. Eng. Pure Sci., Special Issue-I: e66-e74

DOI: 10.7240/jeps.497386

RESEARCH ARTICLE / ARAŞTIRMA MAKALESI

\title{
Farklı Soğutucu Akışkanların Kullanıldığı Kanatlı Borulu Bir Evaporatörün Matematiksel Modeli
}

\author{
Mathematical Modeling of a Finned-Tube Evaporator for Different Refrigerants
}

\author{
Ebru MANÇUHAN ${ }^{1} \mathbb{D}$, Tutku MUTLU ${ }^{2} \mathbb{D}$, Berçem KIRAN-YILDIRIM ${ }^{1} \mathbb{D}$, Sibel TíTiZ-SARGUT ${ }^{1}$ \\ ${ }^{1}$ Marmara Üniversitesi, Mühendislik Fakültesi, Kimya Mühendisliği Bölümü, 34722, İstanbul, Türkiye \\ ${ }^{2}$ Gebze Teknik Üniversitesi, Mühendislik Fakültesi, Kimya Mühendisliği Bölümü, 41400, Kocaeli, Türkiye
}

Öz

Bu çalışmada, farklı soğutucu akışkanlar ve yüzey tiplerinin kullanıldığı kompakt 1sı değiştiricisinin bir evaporatör olarak kullanıldığı durum için matematiksel modeli yapılmıştır. Matematiksel model, EES (Engineering Equation Solver) yazılımı kullanılarak hazırlanmıştır. Model farklı evaporatör yüzey tiplerinde (8.03/8T ve CF-7.0-5/8J), bir doğal (R290) üç sentetik (R410A, R134a, R404A) soğutucu ak1şkan kullanıldığında soğutma kapasitesi $1275 \mathrm{~W}$ için çalışma parametrelerini (kütlesel debi, sıcaklık, basınç) tahmin edebilmektedir. Seçilen soğutucu akışkanların (hidro-floro karbon olan R134a, R404A, R410A ve hidrokarbon R290) küresel ısınma etkisi (GWP) değerleri karş1laştırılarak çevreye olan etkileri belirlenmiştir. Ayrıca geliştirilen model aynı soğutma kapasitesi için farklı soğutucu akışkan ve yüzey tiplerinde evaporatörün buharlaşma (iki fazlı bölge)ile kızgın gaz bölgelerine giren-çıkan havanın sıcaklıklarını, 1sı taşınım katsayılarını, toplam 1sı taşınım katsayılarını ve 1sı transfer hızını tahmin edilebilmektedir. Değişen kütle akısı değerlerinde (50-500 kg/m².s), en yüksek 1s1 taşınım katsayısı iki faz bölgesinde R290 için hesaplanmıştır. Tüm soğutucu akışkanlar karşılaştırıldığında R290'nın diğer sentetik akışkanlara göre daha düşük kütle akısı değerine sahip olduğu görülmüştür. Model sonuçları ve soğutucu akışkanların çevreye olan etkileri göz önünde bulundurulduğunda, R290'nın soğutma sistemlerinde tercih edilebileceği belirlenmiştir.

Anahtar Kelimeler: Evaporatör, Kompakt 1sı değiştiricisi, Soğutma sistemi, Soğutucu akışkan

\begin{abstract}
In this study, various finned tube heat exchangers have been modeled as an evaporator of in which different refrigerants are used. Mathematical model was improved using EES (Engineering Equation Solver) software. The model has been developed which can predict the variable operating parameters (mass flow rate, temperature, pressure) in the compact heat exchanger used as evaporator with two surface types (8.03 / 8T and CF-7.0-5 / 8J) using a natural (R290) and three synthetic refrigerants (R410A, R134a, R404A) for the refrigeration capacity of $1275 \mathrm{~W}$. In addition, the effects of selected refrigerants (R134a, R404A, R410A into hydro-fluoro carbon group and R290 into hydrocarbon group) on the environment were investigated comparing the global warming potential (GWP) values. The proposed model can estimate the inlet and outlet temperatures of air in two different regions (evaporation and superheated gas) of the evaporator, heat convection coefficients, and total heat transfer coefficients and heat transfer rate of all refrigerants for the same refrigeration capacity. The highest heat transfer coefficient in the evaporation zone was calculated for R290 in the range of 50-500 kg/m².s mass flux values. R290 has a lower mass flux compared with all other synthetic refrigerants. Considering the results and environmental effects of refrigerants, it was determined that R290 could be preferred in refrigeration system applications.
\end{abstract}

Keywords: Evaporator, Compact heat exchanger, Refrigeration system, Refrigerant.

\section{I.GIRIŞ}

Mühendislik uygulamalarının en önemli ve en çok karşılaşılan işlemlerinden birisi, farklı sıcaklıklardaki iki veya daha fazla akışkan arasındaki 1sı değişimidir. Bu değişimin yapıldığı cihazlar ısı değiştirici olarak adlandırılır. Pratikte çeşitli yerlerde kullanılan 
1S1 değiştiriciler kullanım amaçlarına göre değişik konstrüksiyonlarda, kapasitelerde, boyutlarda ve tiplerde olabilmektedirler [1]. Endüstride en sık karşılaşılan 1sı değiştirici tipi kompakt 1S1 değiştiricilerdir. Kompakt 1Sı değiştiriciler birim hacim başına çok daha geniş ısı transfer alanları elde edebilmek için özel olarak tasarlanmışlardır. En önemli özellikleri küçük bir hacim içerisinde yüksek ısı transfer hızı sağlamalarıdır. Çok kanatlı, borulu veya levhalı olan kompakt 1sı değiştiriciler genellikle 1s1 taşınım katsayısının küçük ve en az bir akışkanın gaz olduğu durumlarda kullanılmaktadırlar. Kompakt 1sı değiştiricilerde isı transfer hızı artarken boyut, ağırlık ve kullanılan soğutucu akışkan miktarının azaltılması gibi avantajlar sağlanmaktadır [2].

Isı değiştiricilerinin yaygın olarak kullanıldığı alanlardan biri de soğutma uygulamalarıdır. Sanayileşmiş ülkelerde enerji tüketiminin yaklaşı $\% 15$ 'i günümüzde soğutma uygulamalarına bağlanmaktadır. Bu nedenle, soğutma sistemi performanslarının iyileştirilmesi, rasyonel enerji kullanımı bağlamında temel bir konudur [3]. Bu nedenle soğutma sistemlerinin modellenmesi yaklaşık son elli yıldır gündemde olan bir konudur. Soğutma sistemlerinde kullanılan ısı değiştiricilerin davranışlarını karakterize eden birçok model geliştirilmiştir.

Getu ve Bansal tarafından yapılan bir çalışmada çeşitli ampirik korelasyonlardan elde edilen 1sı transfer katsayıları baz alınarak düşük sıcaklıktaki süpermarket soğutucularının evaporatörleri için bir matematiksel model geliştirilmiştir Geliştirilen bu model, kanatçık borulu evaporatördeki buzlanmanın soğutucu performansına etkilerini tahmin etmeye olanak sağlamaktadır [4]. Horton tarafindan yapılan bir başka model çalışmasında ise süpermarket soğutma uygulamalarında ikincil döngülü soğutma sistemlerinin uygulanabilirliği değerlendirilmiştir. Yapılan bu çalışmada soğutma sistemi komponentlerinden evaporator ve kondanserin kanatlı borulu, hava soğutmalı 1sı eşanjörlerinin performansını tahmin etmek için geliştirilmiş ve her bir komponentin sayısal modeli yapılmıştır. Geliştirilen modelin orta sıcaklık $\left(-5,-10,-15^{\circ} \mathrm{C}\right)$ ve düşük sıcaklık uygulamalarını $\left(-20^{\circ} \mathrm{C}\right.$, $-30^{\circ} \mathrm{C}$ ) simüle edebildiği belirtilmiştir [5]. Gövde-borulu bir kondanserin 1sı transfer performansını tahmin edebilmek için matematiksel bir model Tassou ve Green tarafindan geliştirilmiş̧ir. Model 1sı değiştiricisinin geometrik karakteristikleri, akış koşulları, akışkanların giriş sıcaklıklarına göre kızgın, yoğuşma ve aşırı soğuma bölgeleri kesrini, 1Sı transfer katsayılarını, çekilen toplam ısıyı, akışkanın çıkış sıcaklıklarını tahmin edebilecek şekilde geliştirilmiş ve 1sı değiştiricisi analizinde $\varepsilon$-NTU yöntemini kullanılmıştır. Farklı çalışma koşulları için elde edilen model tahminleri tipik bir kondanserden ölçülen verilerle test edilerek doğrulanmıştır [6]. Zabet I. vd. tarafindan yapılan bir çalışmada evaporatör olarak kullanılan farklı yüzey tipinde kanat borulu 1sı değiştiriciler için matematiksel bir model geliştirilmiş ve bu model çalışmasında soğutucu akışkan olarak R152a, R404A, $\mathrm{R} 407 \mathrm{C}, \mathrm{R} 410 \mathrm{~A}, \mathrm{R} 507 \mathrm{~A}$ ve R744 $\left(\mathrm{CO}_{2}\right)$ kullanılırken diğer tarafta akışkan olarak hava seçilmiştir. Geliştirilen model ile soğutucu akışkan tarafında sistem kapasitesi, toplam ve yerel 1Sı taşınım katsayıları, Reynolds sayısı, Nusselt sayısı, akışkan hızı, Prandtl sayısı, Colburn faktörü, sürtünme faktörü ve basınç düşümü parametreleri tahmin edilmiştir. [7].

Liu M. ve Liang S. Y, nemli bir ortamda soğutma sistemlerinde kullanılan kanatlı borulu evaporatörler için soğutucunun akış karakteristiğini ve evaporatördeki hava sıcaklığının dağılımını simüle edebilen bir model geliştirmişlerdir. Ayrıca buharlaştırıcı sıcaklığı ve bağıl nem gibi bazı parametrelerin evaporatörün performansına etkilerini araştırmışlar ve bağıl nemin herhangi bir soğutma sisteminde gerçekten önemli bir parametre olduğu belirtilmiştir [8].

Soğutma sistemlerinde hava ile soğutucu akışkan arasında 1S1 transferini sağlamak için kondanser ve/veya evaporatör olarak en çok tercih edilen 1sı değiştirici tipi, kanat borulu kompakt ısı değiştiricileridir. Soğutma sistemleri tasarımında gerekli zaman ve maliyetin azaltılması, yeni çalışma koşullarına kolayca uyum sağlayabilen modeller ile mümkün olabilmektedir. Bu amaçla, bu çalışmada evaporatör olarak kullanılan kompakt bir ısı değiştiricisinde (yüzey tipi $8.03 / 8 \mathrm{~T}$ ve CF-7.0-5/8J) bir doğal (R290) ve üç sentetik (R410A, R134a, R404A) soğutucu akışkan kullanılarak soğutma kapasitesi $1275 \mathrm{~W}$ için çalışma parametrelerini (kütlesel debi, sıcaklık, basınç) tahmin edebilen bir model geliştirilmiştir. Önerilen model ile aynı soğutma kapasitesi için farklı soğutucu akışkan ve yüzeyler kullanıldığı durumlarda evaporatör iki faz ile kızgın gaz bölgesine giren-çıkan hava sıcaklıkları, ısı taşınım katsayıları, toplam isı transfer katsayıları ve 1si transferini tahmin edilebilmesi amaçlanmıştır. Ayrıca istenilen soğutma kapasitesi ve soğutucu akışkan için evaporatörlerde hangi yüzey tipinin tercih edilmesi gerektiği belirlenebilecektir.

\section{EVAPORATÖR ANALIZİ}

Bu çalışmada evaporatör (kanat borulu 1sı değiştiricisi), hava soğutmalı, karşıt akışlı bir ısı değiştiricisi olarak modellenmiştir. Matematiksel model, EES (Engineering Equation Solver) yazılımı kullanılarak hazırlanmış, modelde transfer olan 1S1 miktarı ve 1Sı taşınım katsayılarının hesaplanması için literatürde mevcut korelasyonlar kullanılmıştır [9,4]. Modelde evaporatöre giren-çıkan akışkanların sıcaklık değerleri ortalama logaritmik sıcaklık farkı (LMTD) yöntemi kullanılarak belirlenmiştir. Evaporatör modelinde Şekil 1'de görüldüğü gibi kızgın gaz ve iki fazlı bölge olarak iki farklı ısı geçiş bölgesi mevcuttur. Bu bölgelerin oranları ve sıcaklık dağılımı akışkanların akış ve yüzey tipine bağlı olarak değişmektedir. Sayısal model için yapılan kabuller şöyle sıralanabilir; 
- Kararlı hal koşulları kabul edilmiştir.

- Hava tarafı ısı taşınım katsayısı $\mathrm{h}_{\mathrm{a}}=100 \mathrm{~W} / \mathrm{m}^{2} \mathrm{~K}$ olarak sabit alınmıştır. [4]

- Soğutucu akışkan tarafında basınç düşüşü ihmal edilmiştir.

- Evaporatör 1sı kaybı veya 1sı kazancı ihmal edilmiştir.

- Evaporatör boru sıra sayısı ve boru uzunluğu sabit kabul edilmiştir.

- Soğutucu akışkanın evaporatör girişinde iki fazlı karışım, evaporatör çıkışında ise kızgın gaz olduğu kabul edilmiştir.

- Evaporatörde kızgın gaz $(\mathrm{F}=0,2)$ ve iki fazlı bölge $(\mathrm{F}=0,8)$ kesirleri kabul edilmiştir.

\subsection{Sayısal Model Çözümü İçin Girdiler}

Model çözümünde soğutucu akışkan ve hava için esas alınan giriş koşulları Tablo 1'de verilmiştir. Evaporatörün bulunduğu ortama giren havanın giriş sıcaklığı, basıncı ve hacimsel debisi sırasıyla $20^{\circ} \mathrm{C}, 100 \mathrm{kPa}$ ve $0.031 \mathrm{~m} 3 / \mathrm{s}$ olarak seçilmiştir. Tüm akışkanların evaporatöre giriş sıcaklıkları $-18,5^{\circ} \mathrm{C}$ olarak kabul edildiğinde, bu sıcaklıktaki akışkanların farklı fiziksel özelliklerinden dolayı EES kullanılarak hesaplanan giriş basınçları Tablo 1'de verilmiştir. Soğutucu akışkana evaporatör kızgın buhar bölgesinde bir miktar 1sı verilerek kompresöre $-10^{\circ} \mathrm{C}$ 'de (sıcaklık farkı $\Delta \mathrm{T}=8,5^{\circ} \mathrm{C}$ olacak şekilde) girdiği kabul edilmiştir. Tablo 1'de görüldüğü gibi sabit evaporatör kapasitesi (1275 W) için, dört farklı akışkanın kütlesel debileri hesaplanmıştır. En düşük kütlesel debi R290 (0,0039 kg/s) en yüksek kütlesel debi ise R404A $(0,0085 \mathrm{~kg} / \mathrm{s})$ için EES yazılımından hesaplanmıştır. R290'nın buharlaşma gizli ısısı değeri buharlaşma sıcaklığı $283 \mathrm{~K}$ için $425,4 \mathrm{~kJ} / \mathrm{kg}$ 'dır ve bu çalışmada seçilen alternatif akışkanlara göre daha büyüktür (Tablo 4). Aynı soğutma kapasitesi için soğutucu akışkanın sahip olduğu buharlaşma gizli ısısı ne kadar yüksek olursa sistemde dolaşan kütlesel debi o kadar az olmakta dolayısıyla kompresör tarafından harcanan enerji azalmaktadır.

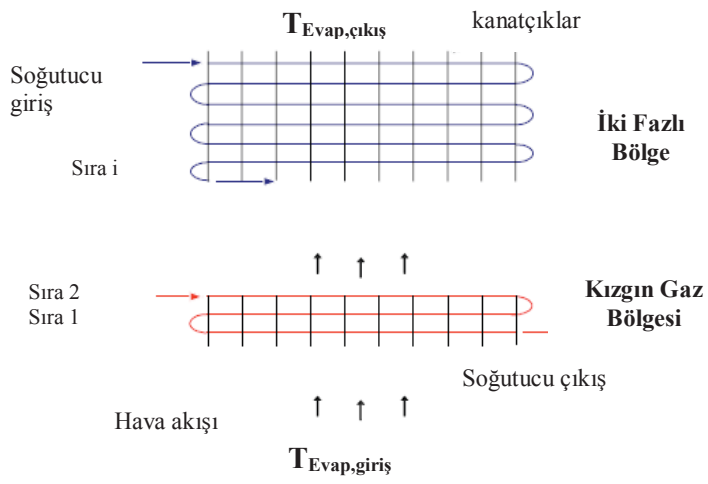

Şekil 1. Tipik bir evaporatörde iki fazlı ve kızgın gaz bölgelerinin şematik gösterimi
Tablo 1. Modelde soğutucu akışkan ve hava için kullanılan veriler

\begin{tabular}{|c|c|c|c|c|c|}
\hline & \multicolumn{4}{|c|}{ Soğutucu tarafi } & \multirow{2}{*}{$\begin{array}{l}\text { Hava } \\
\text { tarafi }\end{array}$} \\
\hline & R134a & R404A & R410A & R290 & \\
\hline Giriş Sıcaklığ $1\left({ }^{\circ} \mathrm{C}\right)$ & \multicolumn{4}{|l|}{$-18,5$} & 20 \\
\hline Çıkış Sicaklığg $1\left({ }^{\circ} \mathrm{C}\right)$ & \multicolumn{4}{|l|}{-10} & -10 \\
\hline Giriş Basıncı (kPa) & 140 & 320,5 & 422,6 & 258 & 100 \\
\hline $\begin{array}{l}\text { Kütlesel Debi } \\
(\mathrm{kg} / \mathrm{s}){ }_{\mathrm{R}}^{\dot{m}}\end{array}$ & 0,0073 & 0,0085 & 0,0063 & 0,00388 & - \\
\hline $\begin{array}{l}\text { Hacimsel Debi } \\
\left(\mathrm{m}^{3} / \mathrm{s}\right) \bar{V}_{\text {air }}\end{array}$ & \multicolumn{4}{|l|}{-} & 0,031 \\
\hline $\begin{array}{l}\text { Evaporatör Kapasi- } \\
\text { tesi (W) }\end{array}$ & \multicolumn{4}{|l|}{$1275 \mathrm{~W}$} & \\
\hline
\end{tabular}

Evaporatör olarak modellenecek 1sı değiştiricisi yüzey tipleri 8.03/8T ve CF-7.0-5/8J olarak seçilmiş ve boru malzemesi bakır, boru tipi ise dairesel kanatçıklı boru olarak esas alınmıştır. Her iki yüzey tipindeki 1sı değiştiricilerin boru uzunluğu $\mathrm{L}=0,06 \mathrm{~m}$, boru sıra say1s1, $N_{t, \text { row }}=10$, boru kolon say1s1, $N_{t, c o l}=2$, bak1r boru iletim katsayıs1, $k_{b a k ı r}=400 \frac{\mathrm{W}}{\mathrm{mk}}$ olarak kabul edilmişstir. Ayrıca, 1S1 değiştiricisi ön yüzey genişlik ve yüksekliği sırası ile $\mathrm{W}=0,25 \mathrm{~m}$, $\mathrm{H}=0,30 \mathrm{~m}$ olarak alınmıştır: Isı değiştiricilerine ait diğer tasarım parametreleri ise Tablo 2.'de verilmiştir. Soğutucu akışkan ile hava arasında transfer edilen 1sıy1 hesaplamak için kullanılan korelasyonlar Tablo 3'de verilmiştir.

Tablo 2. Yüzey tipi 8.0-3/8T ve CF-7.0-5/8J olan 1s1 değiştiricilerinin tasarım parametreleri [2].

\begin{tabular}{|l|l|l|}
\hline Yüzey Tipi & $\mathbf{8 . 0 - 3 / 8 T}$ & CF-7.0-5/8J \\
\hline Boru dış çapı, $\mathrm{D}_{o}(\mathrm{~mm})$ & 10,2 & 16,4 \\
\hline Boru et kalınlığı $(\mathrm{mm})$ & 0,9 & 0,9 \\
\hline Kanat adımı (adet/m) & 315 & 275 \\
\hline $\begin{array}{l}\text { Akış aralığındaki hidrolik çap, } \mathrm{D}_{\mathrm{h}} \\
(\mathrm{mm})\end{array}$ & 3,63 & 6,68 \\
\hline Kanat kalınlığ1, t $(\mathrm{mm})$ & 0,330 & 0,254 \\
\hline Serbest akış alanı/alın alanı, $\sigma$ & 0,534 & 0,449 \\
\hline $\begin{array}{l}\text { Is1 geçiş alanı/toplam hacim }\left(\mathrm{m}^{2} / \mathrm{m}^{3}\right), \\
\alpha\end{array}$ & 587 & 269 \\
\hline Kanat alanı/toplam alan, $\mathrm{A}_{f} / \mathrm{A}$ & 0,913 & 0,83 \\
\hline Borular arası dikey boşluk $S_{v}(\mathrm{~mm})$ & 25,4 & 28,5 \\
\hline Borular arası yatay boşluk $S_{H}(\mathrm{~mm})$ & 22,0 & 16,4 \\
\hline Kanatçık verimi $\eta_{f}$ & 0,89 & 0,89 \\
\hline
\end{tabular}

Tablo 3. Evaporatör modelinde kullanılan korelasyonlar [4] 1) Soğutucu akışkan tarafı ısı taşınım katsayısı

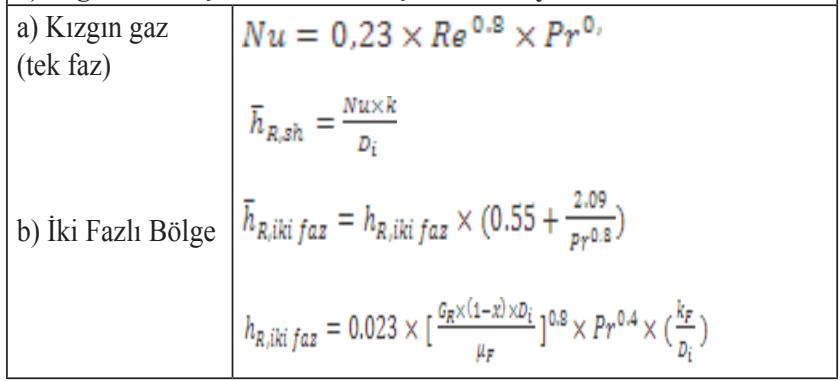




\begin{tabular}{|c|c|}
\hline \multicolumn{2}{|c|}{ 2) Bölgelerin yüzey oranları } \\
\hline $\begin{array}{l}\text { a) Kızgın gaz } \\
\text { b) İki Fazlı Bölge }\end{array}$ & $\begin{array}{l}F_{s h}=0,2 \\
F_{i k i f a z}=0,8\end{array}$ \\
\hline \multicolumn{2}{|c|}{ 3) Soğutucu akışkan tarafı Isıl direnç } \\
\hline $\begin{array}{l}\text { a) Kizgın gaz } \\
\text { b) İki Fazlı Bölge }\end{array}$ & $\begin{array}{l}R_{R, s h}=\frac{1}{h_{R s h} \times \pi \times D_{i} \times L_{s h}} \\
R_{R, i k i \text { jaz }}=\frac{1}{\bar{h}_{R, i k i j a z} \times \pi \times D_{i} \times L_{i k i j a z}}\end{array}$ \\
\hline \multicolumn{2}{|c|}{ 4) Hava tarafı ısıl direnç } \\
\hline $\begin{array}{l}\text { a) Kizgın gaz } \\
\text { b) İki Fazlı Bölge }\end{array}$ & $\begin{array}{l}R_{h, s h=} \frac{R_{h}}{F_{s h}} \\
R_{h, i k i \text { faz }}=\frac{R_{h}}{F_{i k i \text { faz }}}\end{array}$ \\
\hline \multicolumn{2}{|c|}{ 5) Toplam isl direnç } \\
\hline $\begin{array}{l}\text { a) Kızgın gaz } \\
\text { b) İki Fazlı Bölge }\end{array}$ & $\begin{array}{l}R_{s h}=R_{h, s h}+R_{R, s h} \\
R_{i k i} f a z=R_{h, i k i ~ f a z}+R_{R, \text { iki } f a z}\end{array}$ \\
\hline \multicolumn{2}{|c|}{ 6) Toplam IsI transfer katsayısı } \\
\hline $\begin{array}{l}\text { a) Kızgın gaz } \\
\text { b) İki Fazlı Bölge }\end{array}$ & $\begin{array}{l}(U . A)_{\operatorname{sh}}=\frac{1}{R \cdot} \\
(U . A)_{i k i f a z}=\frac{1}{R_{i k i} f a z}\end{array}$ \\
\hline
\end{tabular}

Seçilen soğutucu akışkanların termo-fiziksel özellikleri Tablo 4'de verilmiştir.

Tablo 4. Soğutucu akışkanların termo-fiziksel ve çevresel özellikleri [10].

\begin{tabular}{|l|l|l|l|l|}
\hline & R410a & R134a & R404A & R290 \\
\hline Akışkan sınıfi & HFC & HFC & HFC & HC \\
\hline Kritik Sıcaklı $\left({ }^{\circ} \mathrm{C}\right)$ & 70,2 & 101,1 & 72 & 96,7 \\
\hline Kritik Basınç $(\mathrm{MPa})$ & 4,77 & 4,05 & 3,731 & 4,25 \\
\hline Buharlaşma gizli 1sısı $(\mathrm{kJ} / \mathrm{kg})$ & 256,7 & 217,2 & 200,1 & 425,4 \\
\hline ODP & 0 & 0 & 0 & 0 \\
\hline GWP & 1980 & 1370 & 3700 & $\sim 20$ \\
\hline Güvenlik sınıfi & $\mathrm{A} 1$ & $\mathrm{~A} 1$ & $\mathrm{~A} 1$ & $\mathrm{~A} 3$ \\
\hline
\end{tabular}

Soğutucu akışkanların istenilen soğutma kapasitesi üzerine etkisinin incelendiği bu çalışmada seçilen akışkanlardan biri olan doğal akışkan R290, iyi termodinamik özelliklere sahip kolay bulunabilir, ucuz ve hacimsel kapasitesi yüksek bir soğutucu akışkandır. Bilindiği üzere hacimsel kapasiteleri, belirli çalışma koşulları için gerekli olan kompresörün boyutunun bir ölçüsüdür. Soğutucu akışkanın hacimsel kapasitesi yüksekse kompresör boyutları daha küçük olacaktır. Bundan dolayı soğutma sistemi komponentlerinin de boyutları küçülecektir. Bu da hacimsel kapasitesi 283 K'de 4646,87 $\mathrm{KJ} / \mathrm{m}^{3}$ olan R290 için geleneksel HFC akışkanlarına alternatif soğutucu olabilme şansını arttırmaktadır. Ancak, R290 zehirli olmamasına karşın yüksek yanıcılık sınıfında yer almaktadır [10]. Bu durum R290'nın dezavantajı gibi görünse de düşük şarj miktarlarında kullanıldığında tehlike arz etmemesi uygun tasarımlarla kullanılabilirliğini kolaylaştırmaktadır. R404A, R134a ve R410A akışkanları ise endüstriyel uygulamalarda yaygın bir şekilde kullanıldığından dolayı bu çalışmada sentetik akışkanlar olarak seçilmiştir. Özellikle R134a termo-fiziksel özellerinden (hacimsel kapasitesi 283 K'de 3604,55 kJ/ $\mathrm{m}^{3}$ ) dolayı endüstriyel uygulamalarda çok kullanılan yanıcı ve zehirli olmayan bir akışkandır.

\subsection{Sayısal Model Tarafından Tahmin Edilen Çıktılar}

- Evaporatörde soğutucu akışkandan havaya iki farklı bölgede ısı geçişi $\left(Q_{\text {sh }} ; Q_{i k i f a z}, W / m^{2}\right)$,

$Q_{t}=Q_{i k i f a z}+$

$Q_{i k i f a z}=\dot{\mathrm{m}}_{R}\left(h_{R, i k i f a z, i}-h_{R, i k i f a z, 0}\right)$

$\phi_{\operatorname{sh}}=\dot{\mathrm{m}}_{R}\left(h_{R, \operatorname{sh}, \mathrm{i}}-h_{R, \sin , 0}\right)$

- Havanın iki farklı bölgeye giriş-çıkış sıcaklıkları

$\left(T_{h, s h, 0 ;} T_{h, i k i} f a z, 0\right)$

Evaporatörün iki fazlı bölge ve kızgın gaz bölgesinden havanın çıkış sıcaklıkları ortalama logaritmik sıcaklık farkı (LMTD) yöntemi kullanılarak hesaplanır.

$$
\begin{aligned}
& T_{h, i k i f a z, 0}=T_{h, i k i f a z, i}-\frac{Q_{i k i f a}}{m_{h} \times C p_{h, i k}} \\
& T_{h, i k i f a z, i}=T_{h, s h, 0} \\
& T_{h, s h, 0}=T_{h, s h, i,}+\frac{Q_{s h}}{m_{h} \times C p_{h, s h}} \\
& T_{h, s h, 0}=T_{h, i k i \text { faz,i }}
\end{aligned}
$$

\section{BULGULAR VE TARTIŞMA}

\subsection{Model Simülasyon Sonuçları}

Bu çalışmada, farklı tipte (8.03/8T ve CF-7.0-5/8J) 1sı değiştiricilerinde R134a, R290, R404A ve R410A soğutucu akışkanları kullanıldığında aynı 1sı kapasitesini (1275 W) sağlamak için 1sı taşınım katsayıları ve kütle akısı farklı bölgelerde (kızgın gaz, iki fazlı bölge) model denklemleri kullanılarak hesaplanmıştır. Bu hesaplamalar sırasında kuruluk derecesi $\mathrm{x}=0,5$ olarak kabul edilmiştir. Hesaplanan simülasyon sonuçları detaylı olarak Tablo 5'de verilmiştir. 
Tablo 5. Farklı soğutucu akışkanlar için model sonuçları

\begin{tabular}{|c|c|c|c|c|c|c|c|c|c|c|}
\hline & \multirow[t]{2}{*}{ Yüzey Tipi } & \multicolumn{2}{|c|}{ Toplam Yüzey Alanı $\left(\mathrm{m}^{2}\right)$} & \multicolumn{2}{|c|}{ Taşınım Katsayısı $\left(\mathrm{W} / \mathrm{m}^{2} \mathrm{~K}\right)$} & \multicolumn{2}{|c|}{$\begin{array}{l}\text { Toplam Is1 Taşınım } \\
\text { Katsayısı }\left(\mathrm{W} / \mathrm{m}^{2} \mathrm{~K}\right)\end{array}$} & \multirow{2}{*}{\begin{tabular}{|l|}
$\begin{array}{l}\text { Kütle Ak1s1 }\left(\mathrm{kg} / \mathrm{m}^{2} \mathrm{~s}\right) \\
(\mathrm{x}=0,5)\end{array}$ \\
$\mathbf{G}_{\mathrm{ikifaz}}$ \\
\end{tabular}} & \multicolumn{2}{|c|}{ Is1 Transfer Hız1 (W) } \\
\hline & & $\mathbf{A}_{\mathrm{sh}}$ & $\mathbf{A}_{\mathrm{ik \textrm {if }} \mathrm{f}_{7}}$ & $\mathbf{h}_{\mathrm{sh}}$ & $\mathbf{h}_{\mathrm{ik \textrm {k }} \mathrm{f}_{\mathrm{z}}}$ & $\mathbf{U}_{\mathrm{sh}}$ & $\mathbf{U}_{\mathrm{ik \textrm {k }} \mathrm{f}_{\mathrm{z}}}$ & & $\mathbf{Q}_{\mathrm{s}}$ & $\mathbf{Q}_{\mathrm{kj} f_{27}}$ \\
\hline \multirow{4}{*}{ R134a } & $8.03 / 8 \mathrm{~T}$ & 0,5434 & 2,173 & 284,1 & 795,5 & 11,96 & 26,99 & \multirow{2}{*}{270,6} & 200,3 & 1075 \\
\hline & & \multicolumn{2}{|l|}{2,717} & \multicolumn{2}{|c|}{1079,6} & \multicolumn{2}{|l|}{38,95} & & \multicolumn{2}{|l|}{1275} \\
\hline & CF7.05 & 0,4806 & 1,922 & 166,6 & 483,6 & 13,52 & 30,52 & \multirow{2}{*}{166,8} & 200,3 & 1075 \\
\hline & & \multicolumn{2}{|l|}{2,40} & \multicolumn{2}{|l|}{650,2} & \multicolumn{2}{|l|}{44,04} & & \multicolumn{2}{|l|}{1275} \\
\hline \multirow{4}{*}{ R290 } & $8.03 / 8 \mathrm{~T}$ & 0,5434 & 2,173 & 318,9 & 787 & 13,2 & 26,79 & \multirow{2}{*}{129,8} & 215,2 & 1060 \\
\hline & & \multicolumn{2}{|l|}{2,717} & \multicolumn{2}{|l|}{1105,9} & \multicolumn{2}{|l|}{\begin{tabular}{|l|}
40,00 \\
\end{tabular}} & & \multicolumn{2}{|l|}{1275} \\
\hline & CF7.05 & 0,4806 & 1,922 & 187,5 & 478,1 & 14,93 & 30,29 & \multirow{2}{*}{79,94} & 215,2 & 1060 \\
\hline & & \multicolumn{2}{|l|}{2,40} & \multicolumn{2}{|l|}{665,6} & \multicolumn{2}{|l|}{45,22} & & \multicolumn{2}{|l|}{1275} \\
\hline \multirow{4}{*}{ R404A } & $8.03 / 8 \mathrm{~T}$ & 0,5434 & 2,173 & 331,6 & 778,5 & 13,65 & 26,59 & \multirow{2}{*}{260,5} & 229,8 & 1046 \\
\hline & & \multicolumn{2}{|l|}{2,717} & \multicolumn{2}{|l|}{1110,1} & \multicolumn{2}{|l|}{40,24} & & \multicolumn{2}{|l|}{\begin{tabular}{|l|}
1275 \\
\end{tabular}} \\
\hline & CF7.05 & 0,4806 & 1,922 & 195,1 & 472,7 & 15,43 & 30,06 & 1603 & 229,8 & 1046 \\
\hline & & \multicolumn{2}{|l|}{2,40} & 667,8 & & 45,49 & & 100,3 & 1275 & \\
\hline P4104 & $8.03 / 8 \mathrm{~T}$ & 0,5434 & 2,173 & 288,8 & 799 & 12,13 & 27,08 & 2764 & 194,2 & 1081 \\
\hline R410A & & 2,717 & & 1087,8 & & 39,21 & & $2 / 0,4$ & 1275 & \\
\hline & CF7.05 & 0,4806 & 1,922 & 169,5 & 485,9 & 13,71 & 30,61 & 1704 & 194,2 & 1081 \\
\hline & & 2,40 & & 655,4 & & 44,32 & & $1 / 0,4$ & 1275 & \\
\hline
\end{tabular}

Tablo 5’te görüldüğü gibi 8.03/8T ve CF-7.0-5/8J yüzey tipleri için toplam yüzey alanları sırası ile 2,717 ve $2,40 \mathrm{~m}^{2}$ olarak hesaplanmıştır. Her iki yüzey tipinde de seçilen soğutucu akışkanlar için kızgın buhar bölgesinde 1sı taşınım katsayıları iki fazlı bölgeye göre daha düşük bulunmuştur. Hesaplanan bu model sonuçlarının literatürde mevcut deneysel çalışma sonuçları ile uyumlu olduğu görülmüştür [11]. Ayrıca, tüm soğutucu akışkanlar için toplam ısı transfer yüzey alanı artarken toplam 1sı transfer katsayısının azaldığ 1 tespit edilmiştir. Hesaplanan kütle akısı değerinin hem yüzey tipi hem de soğutucu akışkan tipine bağlı olarak değişkenlik gösterdiği bulunmuştur. Seçilen akışkanlarda 8.03/8T yüzey tipi için hesaplanan kütle akı değerleri CF-7.0-5/8J yüzey tipi için hesaplanan kütle akı değerlerinden daha büyük bulunmuştur. Her iki yüzey tipinde en büyük kütle akı değeri R410A, en küçük kütle akı değeri ise R290 için hesaplanmıştır. R290 için hesaplanan 1sı taşınım ve toplam 1sı transfer katsayılarının diğer soğutucu akışkanlar için hesaplanan değerlerle oldukça yakın olduğu bulunmuştur. Ancak, R290 için hesaplanan kütlesel debinin $(0,00388 \mathrm{~kg} / \mathrm{s})$ diğer akışkanlar ile karşılaştırıldığında oldukça düşük olduğu oluğundan gelecekte soğutma uygulamalarında R290'ının sentetik soğutucu akışkanlara göre iyi bir alternatif olabileceği görülmektedir.

\subsubsection{Evaporatöre giren-çıkan hava ve soğutucu akışkan için hesaplanan sıcaklık değerleri}

Soğutucu akışkanların evaporatör kızgın gaz ve iki fazlı bölgelerine giriş-çıkış sıcaklıkları Tablo 1'de görüldüğü gibi kabul edilmiştir. Bu sıcaklık değerlerine göre farklı akışkanlar için basınç değerleri EES yazılımı kullanılarak belirlenmiştir. Havanın iki fazlı bölge ve kızgın gaz bölgelerinden çıkış sıcaklıkları ise ortalama logaritmik sıcaklık farkı (LMTD) yöntemi kullanılarak Tablo 3'de verilen denklemlerden hesaplanmıştır. Soğutulan ortam sıcaklığ $1-10^{\circ} \mathrm{C}$ 'de olduğu durumda havanın buharlaşma bölgesinden ve kızgın buhar bölgesinden çıkış sıcaklıkları model yardımıyla sırasıyla $15,29^{\circ} \mathrm{C}$ ve $20^{\circ} \mathrm{C}$ olarak tahmin edilmiştir. Bir evaporatör için kabul edilen soğutucu akışkan-hava sıcaklıkları ve tahmin edilen hava sıcaklık değerleri Şekil 2'de görülmektedir.

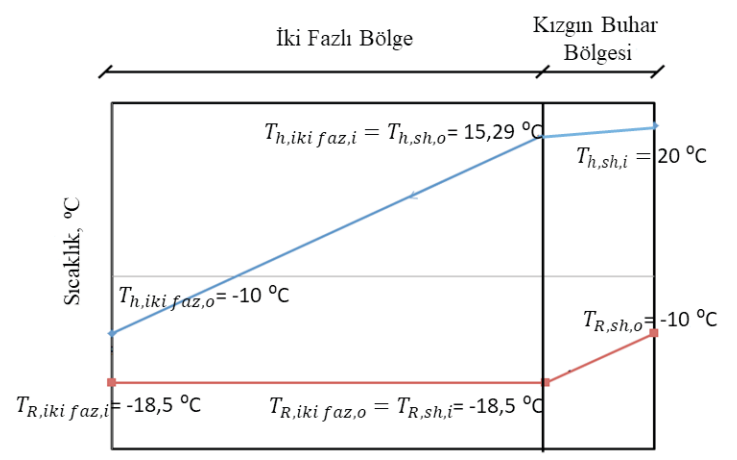

Şekil 2. Soğutucu akışkan ve havanın giriş-çıkış sıcaklıkları

\subsubsection{Farklı soğutucu akışkanlarda kütle akısının ısı taşınım katsayısı üzerine etkisi}

Şekil 3a ve b'de farklı akışkanlar için (R134a, R290, R404A ve R410A) her iki yüzey tipinde kütle akısı değişiminin iki 
faz bölgesi 1sı taşınım katsayısı üzerine etkileri görülmektedir. Yapılan hesaplamalarda 1sı taşınım katsayıları 50 ile $500 \mathrm{~kg} / \mathrm{m}^{2} \mathrm{~s}$ arasında değişen kütle akısı değerleri için bulunmuştur.
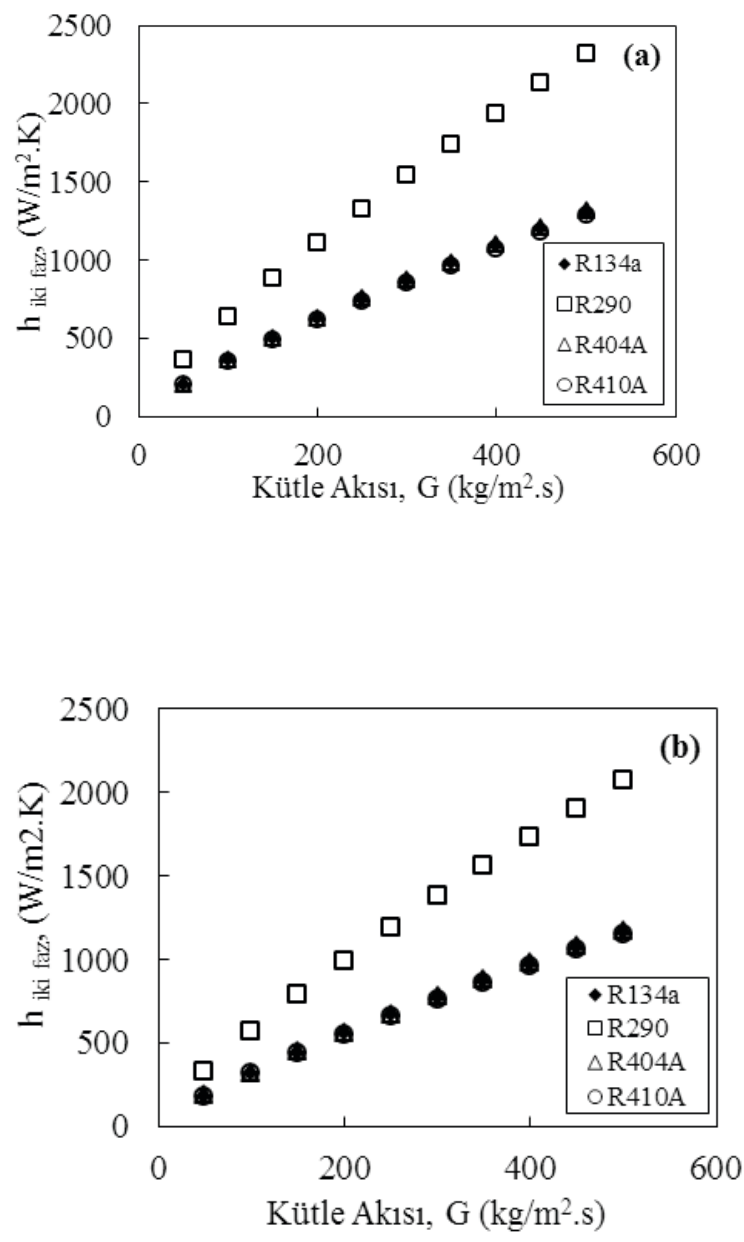

Şekil 3. Farklı akışkanlar için kütle akısının 1sı taşınım katsayısına etkisi (a) YT: 8.0-3/8T (b) YT: CF-7.0-5/8J

Şekil 3a ve b'den açıkça görüldüğü üzere, tüm kütle akısı değerlerinde en yüksek 1sı taşınım katsayısı doğal akışkan olan R290 için elde edilmiştir. Diğer soğutucu akışkanlar için hesaplanan ısı taşınım katsayıları yaklaşık aynı bulunmuştur. R290 için 8.0-3/8T yüzey tipinde 1sı taşınım katsayı değerlerinin $350-2350 \mathrm{~W} / \mathrm{m}^{2} \mathrm{~K}, \mathrm{CF}-7.0-5 / 8 \mathrm{~J}$ yüzey tipinde ise $270-2050 \mathrm{~W} / \mathrm{m}^{2} \mathrm{~K}$ arasında değiştiği görülmüştür. Diğer soğutucu akışkanlar için ısı taşınım katsayıları 8.0-3/8T yüzey tipinde $200-1250 \mathrm{~W} / \mathrm{m}^{2}$.K bulunurken $\mathrm{CF}-7.0-5 / 8 \mathrm{~J}$ yüzey tipinde $125-1100 \mathrm{~W} / \mathrm{m}^{2} \mathrm{~K}$ arasında bulunmuştur.

\subsubsection{Farklı yüzey tiplerinde kütle akısının ısı taşınım katsayısı üzerine etkisi}

Şekil 4(a-b) ve Şekil 5(a-b) seçilen her soğutucu akışkan için farklı yüzey tiplerinde kütle akısının iki fazlı bölgede 1sı taşınım katsayısı üzerine etkisini göstermektedir.
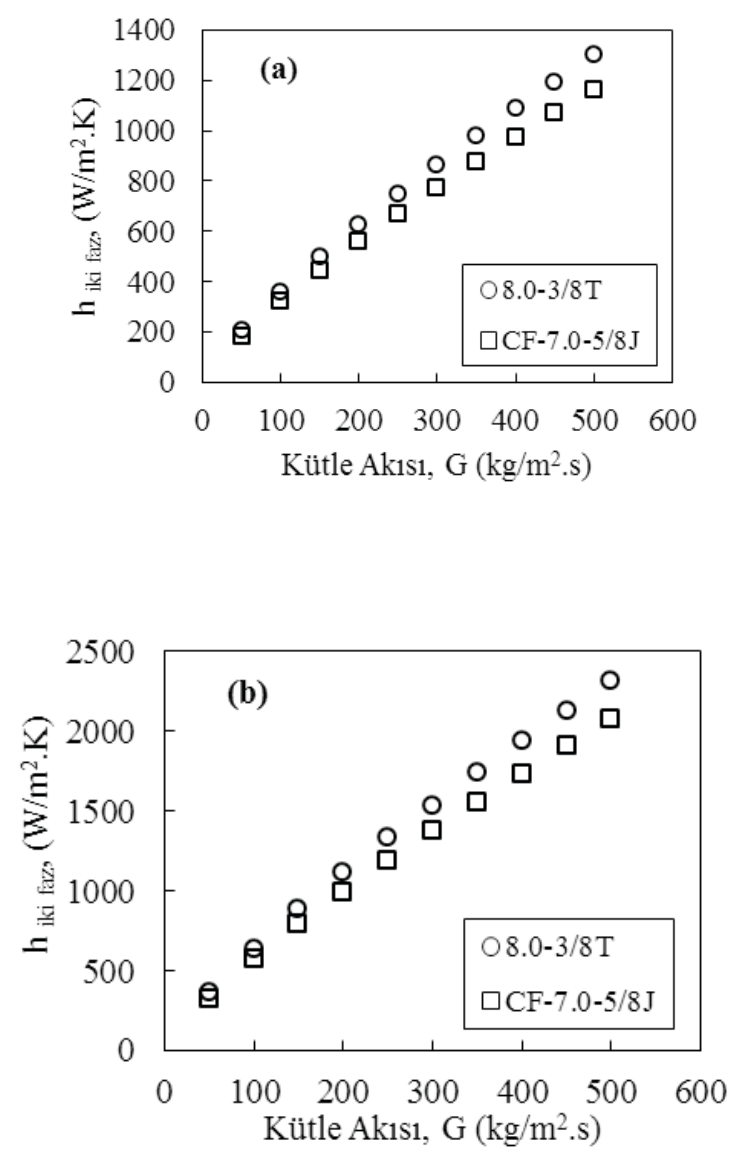

Şekil 4. Farklı yüzey tiplerinde 1sı taşınım katsayısı üzerine kütle akısının etkisi (a) R134a (b) R290

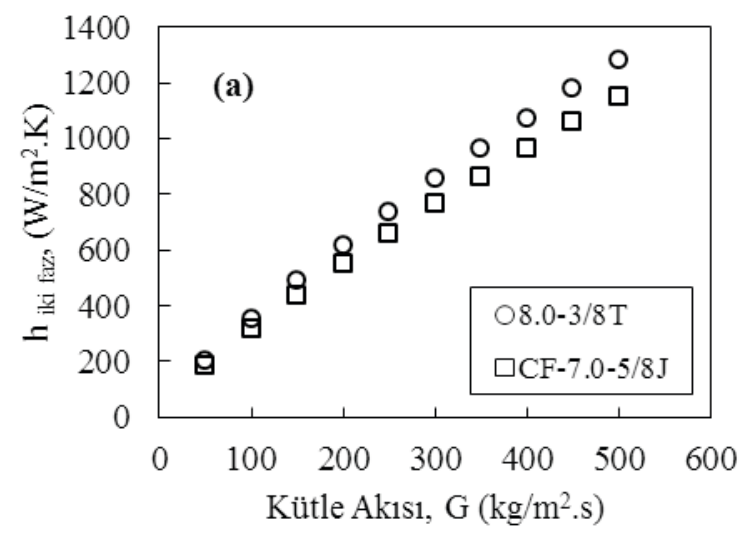




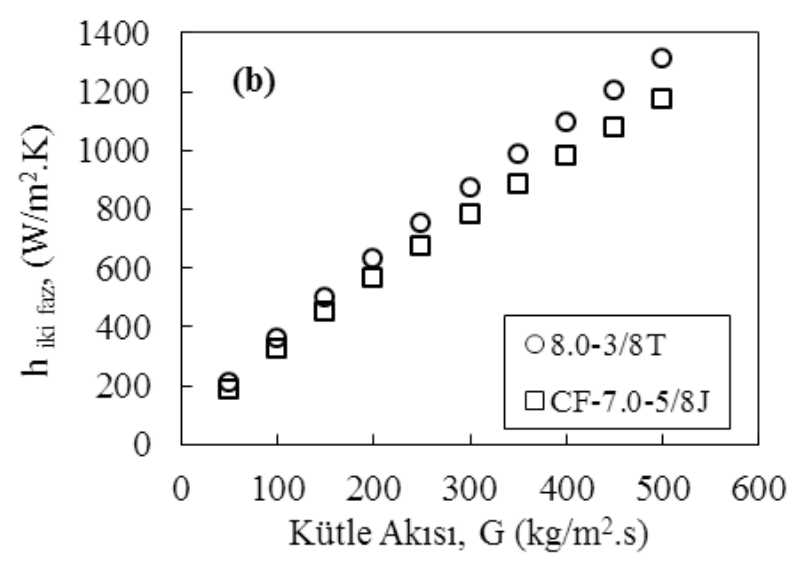

Şekil 5. Farklı yüzey tiplerinde 1sı taşınım katsayısı üzerine kütle akısının etkisi (a) R410A (b) R404A

Literatürde [11] tasarım parametresi $\propto$, evaporatör olarak kullanılan kompakt 1S1 değiştiricilerinin toplam hacmi başına 1sı transfer yüzey alanı olarak tanımlanmaktadır. 8.0-3/8T tipi evaporatörde $\propto$ değeri $587 \mathrm{~m}^{2} / \mathrm{m}^{3}$ iken CF-7.05/8J tipinde $\propto$ değeri $269 \mathrm{~m}^{2} / \mathrm{m}^{3}$ olarak verilmiştir(Tablo 2). Ayrıca $8.0-3 / 8 \mathrm{~T}$ tipi ve CF-7.0-5/8J tipi kanatçık sayısı sirasiyla 315 adet/metre ve 275 adet/metre' dir. Şekil 5'den 8'e kadar görüldüğü gibi kütle akısının $50 \mathrm{~kg} / \mathrm{m}^{2} \mathrm{~s}-500 \mathrm{~kg} /$ $\mathrm{m}^{2} \mathrm{~s}$ değerleri arasında 8.0-3/8T tipi için hesaplanan taşınım katsayısı değerleri, CF-7.0-5/8J tipi için hesaplanan taşınım katsayısı değerlerinden daha yüksektir. Bilindiği üzere, $\propto$ ve birim uzunluk için kanatçık sayısı değerlerinin büyük olması 1sı taşınım katsayılarının da büyük olmasına sebep olmaktadır. Bu sebepten 8.0-3/8T yüzey tipi kullanıldığında hesaplanan 1sı taşınım katsayılarının CF-7.0-5/8J yüzey tipi için hesaplanan $1 s ı$ taşınım katsayılarından daha büyük olduğu görülmüştür.

\subsubsection{Kuruluk derecesinin kütle akısına etkisi}

Şekil 6a ve b'de seçilen soğutucu akışkanların her iki yüzey tipi için iki faz bölgesinde kuruluk derecesinin kütle akısına etkisi görülmektedir. İki faz bölgesinde kütle akısı hesaplamaları 0,1-0,9 arasında değişen kuruluk derecesi değerleri için yapılmıştır. Şekil 6a ve b'den görüldüğü gibi kuruluk derecesine karşı kütle akısındaki değişim tüm akışkanlar için benzer bir davranış göstermektedir. Kütle akısı, kuruluk derecesinin 0,3 değerine kadar ani bir düşme eğilimi gösteriyor iken, 0,3-0,9 değerleri arasında bu düşme eğiliminin daha yavaş gerçekleştiği görülmektedir. Aynı 1sıyı çekmek için, sıvı fazdan gaz fazına dönen soğutucu akışkan için gereken kütle akısının daha az olacağı düşünülürse akışkanların gösterdiği bu davranış beklenen bir durumdur. Şekil 6a ve b'den görüldüğü gibi her iki yüzey tipinde R290 için aynı kuruluk derecesi değerlerinde sentetik akışkanlara göre daha düşük kütle akısı değerleri bulunmuştur. R290 alternatif olan akışkanların birbirine çok yakın kütle akısı değerlerine sahip olduğu görülmektedir.
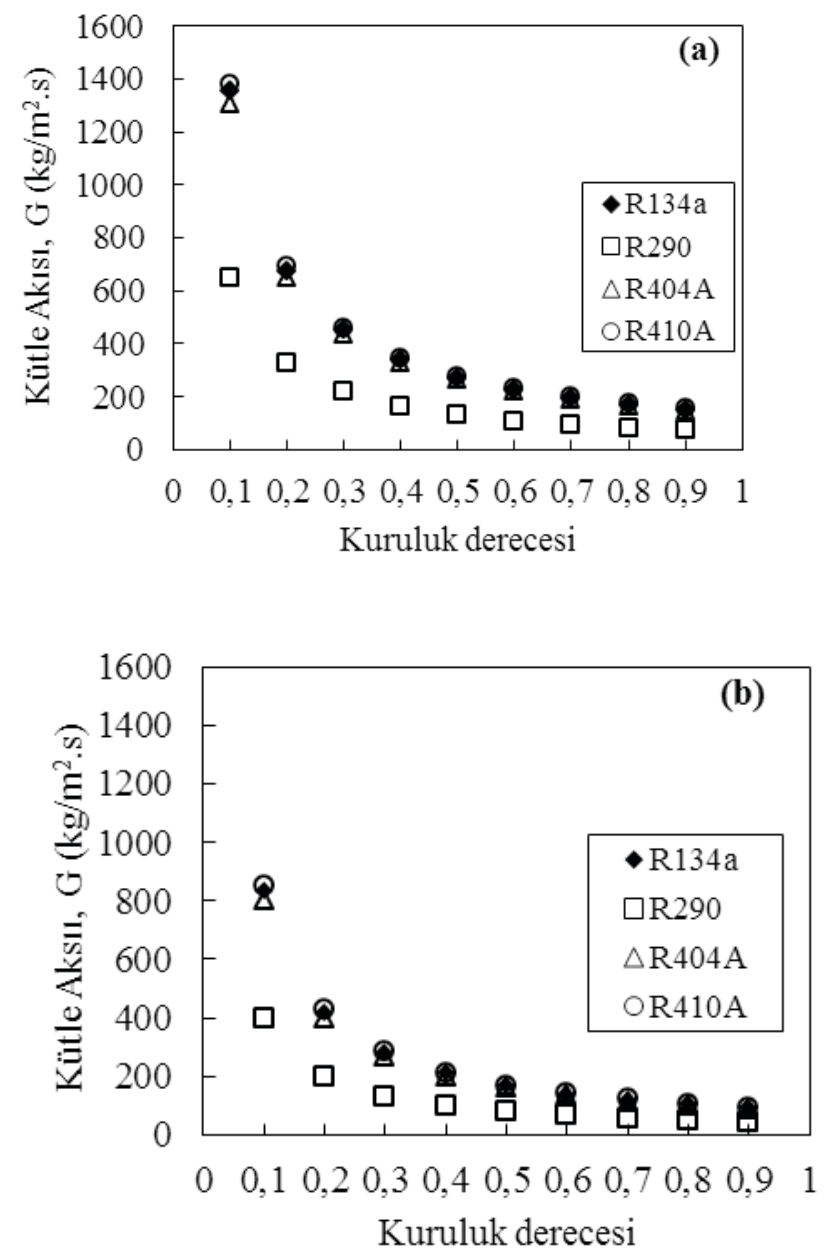

Şekil 6. Kuruluk derecesinin kütle akısına etkisi (a) 8.0-3/8T yüzey tipi (b) CF-7.0-5/8J yüzey tipi

Farklı yüzey tiplerinde kuruluk derecesinin kütle akısı üzerine etkisi, R290 ve birbirine çok yakın kütle akısı değerlerine sahip diğer sentetik soğutucu akışkanları temsilen R134a için Şekil 7a ve b'de gösterilmiştir. Her iki akışkan için değişen kuruluk derecesine bağlı olarak hesaplanan kütle akısı değerleri 8.0-3/8T yüzey tipi için CF-7.0-5/8J yüzey tipine göre daha yüksek bulunmuştur. 

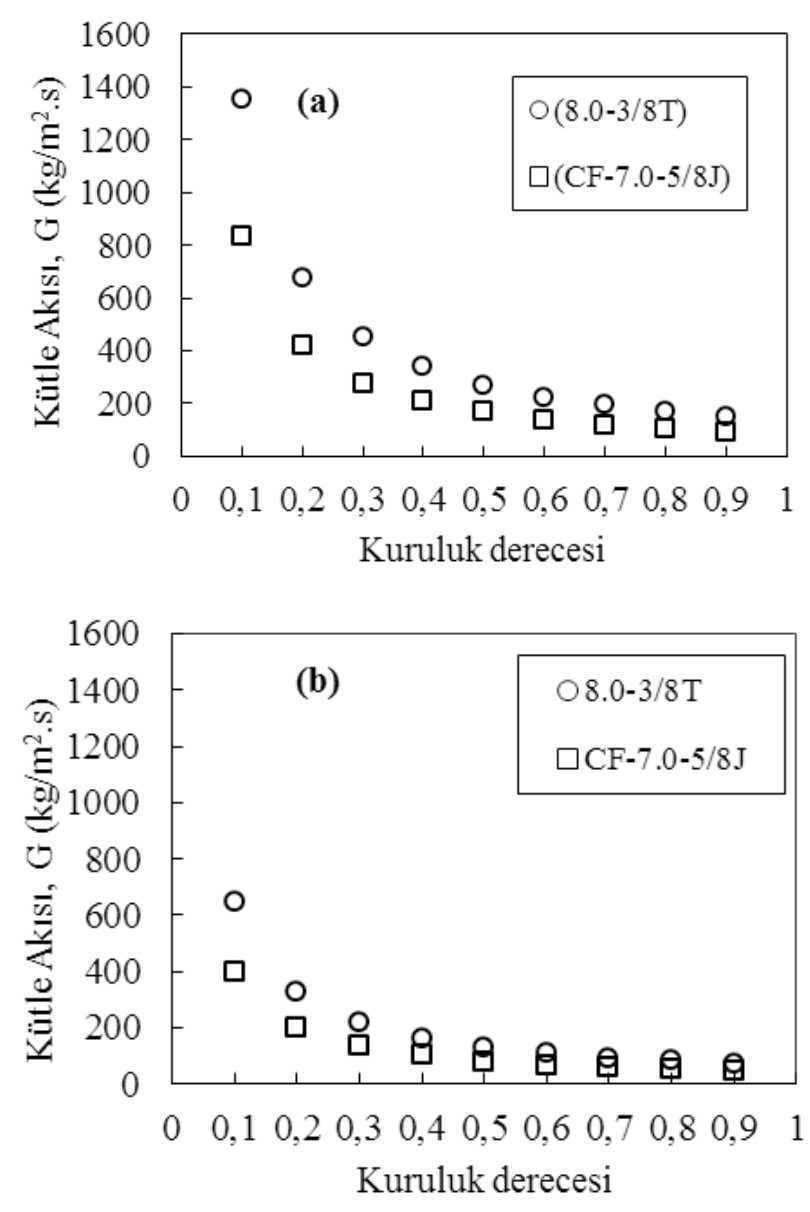

Şekil 7. Kütle akısına kuruluk derecesinin etkisi (a) R134a (b) R290

\subsubsection{Sonuç ve değerlendirmeler}

$\mathrm{Bu}$ çalışmada evaporatör olarak kullanılan kompakt bir 1S1 değiştiricisinde farklı soğutucu akışkanların (R134a, R404A, R290 ve R410A) değişen çalışma parametrelerinde (kütlesel debi, sıcaklık, basınç) soğutma kapasitesi üzerine etkilerini tahmin edebilen bir model geliştirilmiştir. Önerilen model ile evaporatör iki fazlı ve kızgın gaz bölgesine giren-çıkan hava sıcaklıkları, ısı taşınım katsayıları, toplam ısı transfer katsayıları ve 1sı transferi tahmin edilmiştir. Model sonuçları aşağıda verilmiştir:

- Her iki yüzey tipi için tüm soğutucu akışkanlarda kızgın buhar bölgesinde 1sı taşınım katsayıları iki fazlı bölgeye göre daha düşük bulunmuştur. Isı transfer yüzey alanının artışıyla toplam ısı transfer katsayısının azaldığı tespit edilmiştir.

- Kütle akısının evaporatör yüzey tipi ve soğutucu akışkan özelliklerinden etkilendiği görülmüştür. 8.03/8T yüzey tipi için hesaplanan kütle akı değerleri
CF-7.0-5/8J yüzey tipi için hesaplanan kütle ak1 değerlerinden daha büyük bulunmuştur.

- $\quad$ En düşük kütle debisi R290 için 0,00388 kg/s olarak hesaplanmıştır. Diğer akışkanlar için ise hesaplanan kütle debisi değerleri birbirlerine oldukça yakın bulunmuştur.

- Tüm kütle akısı değerlerinde en yüksek 1sı taşınım katsayıs1, R290 için 8.0-3/8T yüzey tipinde 350$2350 \mathrm{~W} / \mathrm{m}^{2}$.K arasında elde edilirken, diğer soğutucu akışkanlar için 1sı taşınım katsayıları aynı yüzey tipinde $200-1250 \mathrm{~W} / \mathrm{m}^{2}$.K olarak bulunmuştur.

- $\quad$ R290 için en düşük kütle debisi 0,0039 kg/s olarak hesaplanmıştır. Diğer akışkanlar için hesaplanan kütle debi değerleri birbirlerine oldukça yakın bulunmuştur.

- Elde edilen model sonuçlarına göre evaporatör olarak kullanılan 8.0-3/8T yüzey tipine sahip kompakt 1s1 değiştiricilerinde R290'nın sentetik soğutucu akışkanlara göre iyi bir alternatif olabileceği görülmektedir. Ayrıca R290'nın GWP (11) değerinin diğer HFC grubu soğutucu akışkanların GWP değerlerine (1370-3700) göre çok düşük olması da gelecekte çevre dostu akışkanlar arasında yer alacağını göstermektedir.

\section{TEŞEKKÜR}

$\mathrm{Bu}$ çalışma FEN-C-YLP-110.117.0023 numaralı Marmara Üniversitesi BAPKO Lisansüstü Tez projesi kapsamında desteklenmiştir.

\section{KAYNAKLAR}

[1] BAYRAM, G., \& ŞAHIN, A. Ş. Plakalı Isı Eşanjöründe Farklı Soğutkanlar Kullanılarak İki Farklı Soğutma Sisteminin Deneysel Analizi. SDÜ Yekarum e-Dergi, 2(2).

[2] Incropera F. P., DeWitt D. P., (1990). Fundamental of heat and mass transfer. John Wiley, New York.

[3] US Environmental Protection Agency, National Action Plan for Energy Efficiency: Sector Collaborative on Energy Efficiency Accomplishments and Next Steps.

Available:<http://www.epa.gov/cleanenergy/documents/ suca/sector_collaborative.pdf $>$.

[4 Getu, H. M., \& Bansal, P. K. (2007). Modeling and performance analyses of evaporators in frozen-food supermarket display cabinets at low temperatures. International Journal of Refrigeration, 30(7), 1227-1243.

[5] Horton, W.T., (2002). Modeling of secondary loop refrigeration systems in supermarket applications, Ph.D. Thesis, Purdue University, USA.

[6] Tassou, S. A., \& Green, R. K. (1981). A mathematical model of the heat transfer process in a shell and tube condenser for 
use in refrigeration applications. Applied Mathematical Modelling, 5(1), 29-33.

[7] Zabet, I., Lemort, V., \& TÂRLEA, G. M. (2012). Mathematical model of a heat exchanger working with different refrigerants., Mathematical Modelling in Civil Engineering, 55.

[8] Liu, M., Liang, S. Y., Wong, T. N., \& Nathan, G. K. (1997, September). Performance Study of Finned Tube Evaporators in a Humid Environment. In ASME 1997 Turbo Asia Conference(pp. V001T13A007-V001T13A007). American Society of Mechanical Engineers.

\section{SEMBOLLER}

\begin{tabular}{|c|c|}
\hline A & Toplam yüzey alanı $\left[\mathrm{m}^{2}\right]$ \\
\hline$A_{\text {fr }}$ & Ön yüzey alanı (alın alanı) $\left[\mathrm{m}^{2}\right]$ \\
\hline$A_{f} / A$ & Kanat alanı/toplam yüzey alanı $\left[\mathrm{m}^{2} / \mathrm{m}^{2}\right]$ \\
\hline $\mathrm{A} / \mathrm{A}_{\mathrm{fr}}$ & Toplam yüzey alanı/Alın alanı [-] \\
\hline $\mathrm{C}_{\mathrm{p}}$ & Sabit basınçta özgül 1sı, [J/kg.K] \\
\hline $\mathrm{D}$ & Boru çap1 $[\mathrm{mm}]$ \\
\hline $\mathrm{D}_{\mathrm{O}}$ & Boru dış çap1 $[\mathrm{mm}]$ \\
\hline $\mathrm{D}_{\mathrm{h}}$ & Boru hidrolik çap1 çapı $[\mathrm{mm}]$ \\
\hline$f$ & Sürtünme faktörü \\
\hline $\mathrm{F}$ & Bölge kesri [-] \\
\hline G & Kütlesel ak1 [kg/s.m²] \\
\hline h & Taşınım katsayısı [W/m².K] \\
\hline $\mathrm{H}$ & Isı değiştiricisi yüksekliği [m] \\
\hline $\mathrm{J}$ & Isı geçişi için Colburn J faktörü \\
\hline $\mathrm{k}$ & Is1 iletim katsay1s1 [W/m.K] \\
\hline $\mathrm{L}$ & Is1 değisştiricisi uzunluğu [m] \\
\hline$\dot{\mathrm{m}}$ & Kütlesel debi $[\mathrm{kg} / \mathrm{s}]$ \\
\hline $\mathrm{Nu}$ & Nusselt say1sı [-] \\
\hline $\mathrm{N}_{\mathrm{t}, \text { row }}$ & Boru sıra sayis1 \\
\hline $\mathrm{N}_{\mathrm{t}, \mathrm{col}}$ & Boru kolon say1s1 \\
\hline $\operatorname{Pr}$ & Prandtl say1s1 \\
\hline Q & Enerji geçişi [W] \\
\hline $\operatorname{Re}$ & Reynolds say1s1 \\
\hline St & Stanton say1s1 \\
\hline $\mathrm{t}$ & Kanatçık kalınlığı [mm] \\
\hline $\mathrm{T}$ & Sicaklık $\left[{ }^{\circ} \mathrm{C}, \mathrm{K}\right]$ \\
\hline
\end{tabular}

[9] EES; (2017). Engineering Equation Solver, Academic Commercial, V10.326, fChart Software Inc.

[10] Stocker, T. F., Qin, D., Plattner, G. K., Tignor, M., Allen, S. K., Boschung, J., ... \& Midgley, B. M. (2013). IPCC, 2013: climate change 2013: the physical science basis. Contribution of working group I to the fifth assessment report of the intergovernmental panel on climate change.

[11] Bergman, T. L., Incropera, F. P., DeWitt, D. P., \& Lavine, A. S. (2011). Fundamentals of heat and mass transfer. John Wiley \& Sons.

$\begin{array}{ll}\mathrm{U} & \text { Toplam isı geçiş katsayısı }\left[\mathrm{W} / \mathrm{m}^{2} . \mathrm{K}\right] \\ v & \text { Özgül hacim }\left[\mathrm{m}^{3} / \mathrm{kg}\right] \\ \mathrm{V} & \text { Isı değiştirici hacmi }\left[\mathrm{m}^{3}\right] \\ V & \text { Hacimsel debi }\left[\mathrm{m}^{3} / \mathrm{s}\right] \\ \mathrm{W} & \text { Isı değiştiricisi genişliği }[\mathrm{m}] \\ \mathrm{W} & \text { Birim zamanda yapılan iş }[\mathrm{W}] \\ \mathrm{HFC} & \text { Hidroflorokarbon } \\ \mathrm{HC} & \text { Hidrokarbon }\end{array}$

\section{Yunan harfleri}

$\begin{array}{ll}\rho & \text { Yoğunluk, }\left[\mathrm{kg} / \mathrm{m}^{3}\right] \\ \sigma & \text { Serbest akış alanı/alın alanı, }\left[\mathrm{m}^{2} / \mathrm{m}^{2}\right] \\ \alpha & \text { Isı geçiş alanı/toplam hacim, }\left[\mathrm{m}^{2} / \mathrm{m}^{3}\right] \\ \eta & \text { Verim } \\ \mu & \text { Kinematik viskozite, }\left[\mathrm{m}^{2} / \mathrm{s}\right]\end{array}$

\begin{tabular}{ll}
\multicolumn{2}{l}{ Alt indisler } \\
h,i & hava giriş sıcaklığı \\
h,o & hava çıkış sıcaklığı \\
c & Soğuk \\
h & Sicak \\
max & maksimum \\
R & soğutucu akışkan \\
iki faz & buharlaşma \\
sh & kızgın gaz \\
total & toplam
\end{tabular}

